\title{
Tear Secretion Induced by Selective Stimulation of Corneal and Conjunctival Sensory Nerve Fibers
}

\author{
M. Carmen Acosta, ${ }^{1}$ Assumpta Peral, ${ }^{2}$ Carolina Luna, ${ }^{1}$ Jesús Pintor, ${ }^{3}$ Carlos Belmonte, ${ }^{1}$ \\ and Juana Gallar ${ }^{1}$
}

Purpose. To measure the increase in tear secretion evoked by selective stimulation of the different populations of sensory receptors of the cornea and conjunctiva by using moderate and intense mechanical, chemical, and cold stimuli.

Methods. Six healthy subjects participated in the study. Tear secretion was measured in both eyes by the Schirmer's test conducted under control conditions and after stimulation of the center of the cornea and the temporal conjunctiva with a gas esthesiometer. Mechanical stimulation consisted in three pulses of 3 seconds' duration of warmed air (at $34^{\circ} \mathrm{C}$ on the eye surface) applied at moderate $(170 \mathrm{~mL} / \mathrm{min})$ and high $(260$ $\mathrm{mL} / \mathrm{min}$ ) flow rates. Cold thermal stimulation was made with cooled air that produced a corneal temperature drop of $-1{ }^{\circ} \mathrm{C}$ or $-4.5^{\circ} \mathrm{C}$. Chemical (acidic) stimulation was performed with a jet of gas containing a mixture of $80 \% \mathrm{CO}_{2}$ in air.

Results. The basal volume of tear secretion increased significantly $(P<0.05$, paired $t$-test $)$ after stimulation of the cornea with high-flow mechanical stimuli $(260 \mathrm{~mL} / \mathrm{min})$, intense cooling pulses $\left(-4.5^{\circ} \mathrm{C}\right)$, and chemical stimulation $\left(80 \% \mathrm{CO}_{2}\right)$. The same stimuli were ineffective when applied to the conjunctiva. Moderate mechanical $(170 \mathrm{~mL} / \mathrm{min})$ and cold $\left(-1^{\circ} \mathrm{C}\right)$ stimulation of the cornea or the conjunctiva did not change significantly the volume of tear secretion.

Conclusions. Reflex tear secretion caused by corneal stimulation seems to be chiefly due to activation of corneal polymodal nociceptors, whereas selective excitation of corneal mechanonociceptors or cold receptors appears to be less effective in evoking an augmented lacrimal secretion. Conjunctival receptors stimulated at equivalent levels do not evoke an increased tear secretion. (Invest Ophthalmol Vis Sci. 2004;45: 2333-2336) DOI:10.1167/iovs.03-1366

$\mathrm{T}$ earing is associated with emotional upset and with vomiting, coughing, and yawning. Basal tear secretion also increases in response to a variety of irritants applied to the ocular surface or the nasal and oral mucosae. This reflex augmenta-

From the ${ }^{1}$ Instituto de Neurociencias de Alicante, Universidad Miguel Hernández-CSIC, Campus de San Juan, San Juan de Alicante, Spain.; and the Departmentos de ${ }^{2}$ Óptica and de ${ }^{3}$ Bioquímica, Escuela Universitaria de Óptica, Universidad Complutense de Madrid, Madrid, Spain.

Supported by Grants MCYTBFI2002-03788 from Ministerio de Ciencia y Tecnología, Spain; FISS PI020945 and 01/1162 from Instituto de Salud Carlos III, Spain; and CTIDIB/2002/140 from Generalitat Valenciana, Spain.

Submitted for publication December 17, 2003; revised February 17 and March 8, 2004; accepted March 9, 2004.

Disclosure: M.C. Acosta, None; A. Peral, None; C. Luna, None; J. Pintor, None; C. Belmonte, None; J. Gallar, None

The publication costs of this article were defrayed in part by page charge payment. This article must therefore be marked "advertisement" in accordance with 18 U.S.C. $\$ 1734$ solely to indicate this fact.

Corresponding author: M. Carmen Acosta, Instituto de Neurociencias de Alicante, Universidad Miguel Hernández-CSIC, Campus de San Juan, Aptdo. 18, 03550 San Juan de Alicante, Spain;

mcarmen.acosta@umh.es. tion of tear production can be prevented by damage to the sensory root of the trigeminal nerve or by topical application of cocaine and other local anesthetic drugs onto the eye. ${ }^{1}$ This suggests that the afferent branch of the tearing response to ocular surface irritation is formed by sensory axons of trigeminal ganglion neurons supplying the eye. The efferent pathway of this reflex is formed by parasympathetic fibers of the facial nerve and sympathetic fibers of the superior cervical nerve $\mathrm{e}^{2,3}$ that act on the main and accessory lacrimal glands, meibomian glands, and ocular surface epithelia to regulate the production of proteins, electrolytes, water, and mucins of the tear film. ${ }^{4,5}$

The sensory innervation of the cornea and the conjunctiva includes different functional classes of sensory receptor fibers identified as mechanonociceptor, polymodal nociceptor, and cold receptor fibers. ${ }^{6-9}$ In addition, a small number of lowthreshold mechanoreceptor nerve endings are found in the limbus and perilimbal bulbar conjunctiva. ${ }^{7}$ Separate stimulation of the various types of ocular sensory afferents evokes sensations of different quality that may contain a component of irritation, depending on the intensity and modality of the stimulus. ${ }^{10,11}$ However, the relative contribution to reflex tear secretion of the different functional subpopulations of corneal and conjunctival sensory afferents is still undefined. The purpose of this study was to compare the changes in tear secretion induced by selective stimulation of the functionally distinct types of sensory receptor fibers supplying the cornea and bulbar conjunctiva.

\section{Materials AND Methods}

\section{Subjects}

Six subjects of both sexes (two men and four women; age range, 26-36 years; mean age, $30.5 \pm 1.8$ ) participated voluntarily in this study. The research adhered to the tenets of the Declaration of Helsinki. The subjects signed an informed consent and were free to interrupt the session at any time. None of the individuals had any ocular disease. The McMonnies test was performed to exclude subjects who had symptoms of a dry eye condition.

\section{Esthesiometry and Tear Collection}

The cornea and the conjunctiva were stimulated with a gas esthesiometer. ${ }^{12}$ For this purpose, three gas pulses lasting 3 seconds each, of variable flow rate, temperature, and $\mathrm{CO}_{2}$ content, were applied sequentially (interval $<0.5$ seconds) to the center of the cornea or to the temporal side of the bulbar conjunctiva. Subjects were asked to avoid blinking during the application of the three gas pulses. Mechanical stimulation was obtained with air puffs of moderate $(170 \mathrm{~mL} / \mathrm{min})$ or high $(260 \mathrm{~mL} / \mathrm{min})$ flow. Chemical stimulation was performed using gas pulses that contained $80 \% \mathrm{CO}_{2}$ in air, applied at subthreshold flow rates. In both cases, the gas was warmed inside the probe to reach the surface of the cornea at a temperature of $34^{\circ} \mathrm{C}^{10,12}$ Air pulses, cooled to evoke temperature decreases on the surface of the cornea or conjunctiva of $-1{ }^{\circ} \mathrm{C}$ or $-4.5^{\circ} \mathrm{C}$, and at a gas flow below mechanical threshold, were used for thermal stimulation. ${ }^{10,11}$ Subjects were requested to define the sensation evoked by the stimulus as irritating or 
TABle 1. Example of a Sequence of Experimental Sessions

\begin{tabular}{|c|c|c|}
\hline Session & Stimulus Type & Eye \\
\hline 1 & No stimulus & Both eyes \\
\hline 2 & Cornea: mechanical, moderate & $\begin{array}{l}\text { First eye } \\
\text { Second eye ( } 15 \text { min later) }\end{array}$ \\
\hline 3 & Cornea: mechanical, strong & $\begin{array}{l}\text { First eye } \\
\text { Second eye ( } 15 \text { min later) }\end{array}$ \\
\hline 4 & Cornea: cold, moderate & $\begin{array}{l}\text { First eye } \\
\text { Second eye ( } 15 \mathrm{~min} \text { later) }\end{array}$ \\
\hline 5 & Cornea: cold, strong & $\begin{array}{l}\text { First eye } \\
\text { Second eye ( } 15 \mathrm{~min} \text { later) }\end{array}$ \\
\hline 6 & Cornea: chemical & $\begin{array}{l}\text { First eye } \\
\text { Second eye (15 min later) }\end{array}$ \\
\hline 7 & Conjunctiva: mechanical, moderate & $\begin{array}{l}\text { First eye } \\
\text { Second eye ( } 15 \mathrm{~min} \text { later) }\end{array}$ \\
\hline 8 & Conjunctiva: mechanical, strong & $\begin{array}{l}\text { First eye } \\
\text { Second eye ( } 15 \text { min later) }\end{array}$ \\
\hline 9 & Conjunctiva: cold, moderate & $\begin{array}{l}\text { First eye } \\
\text { Second eye ( } 15 \mathrm{~min} \text { later) }\end{array}$ \\
\hline 10 & Conjunctiva: cold, strong & $\begin{array}{l}\text { First eye } \\
\text { Second eye ( } 15 \mathrm{~min} \text { later) }\end{array}$ \\
\hline 11 & Conjunctiva: chemical & $\begin{array}{l}\text { First eye } \\
\text { Second eye ( } 15 \text { min later) }\end{array}$ \\
\hline
\end{tabular}

In each subject, the order of the different stimuli and the tissue stimulated was established at random before the experiment.

innocuous. They also described in their own words the characteristics of the experienced sensation.

Eleven measurements of tear secretion per eye were performed in each subject, distributed in 11 separate sessions: 1 without stimulation and 10 in which the various forms of stimulation (mechanical moderate, mechanical strong, cold moderate, cold strong, and chemical) were applied to the cornea or the conjunctiva (Table 1). Basal tear production was measured once at the beginning of the experimental series (session 1). The order of the remaining sessions was established at random. In every session, one eye was randomly selected and stimulated sequentially while tears of that eye were collected; 15 minutes later, the same procedure was repeated in the second eye. At least 4 hours were allowed between successive sessions.

Tear production was measured using the Schirmer test. ${ }^{13}$ The Schirmer strip was applied on the temporal tarsal conjunctiva of the lower lid before stimulation (to measure basal secretion in the first session) or immediately after the end of the stimulation period (to measure the tear secretion consecutive to the different stimuli) and maintained in place for 5 minutes. The volume of secretion was expressed as millimeters of moistened strip. Data are presented as the mean \pm SEM of the results in all subjects and compared by using the paired $t$-test.

\section{Results}

\section{Corneal Stimulation}

No significant changes in tear secretion were observed when the cornea was stimulated mechanically with air pulses of moderate intensity (flow: $170 \mathrm{~mL} / \mathrm{min}$ ). Similarly, application of cold pulses leading to a temperature reduction of the corneal surface of $-1{ }^{\circ} \mathrm{C}$, failed to increase significantly the basal values of tear secretion (Fig. 1A). In contrast, mechanical stimuli with high air flows $(260 \mathrm{~mL} / \mathrm{min})$, with pulses containing $80 \% \mathrm{CO}_{2}$, and with cold air pulses that reduced corneal temperature by $-4.5^{\circ} \mathrm{C}$ increased tear secretion significantly $(P<$ 0.05 , paired $t$-test; Fig. 1A). The responses to stimuli of the first and the second eye were not significantly different (paired $t$-test, data not shown). All corneal stimuli used in the present experiments were suprathreshold, and their application was clearly identified in all cases. However, only mechanical and chemical stimuli of high intensity $\left(260 \mathrm{~mL} / \mathrm{min}, 80 \% \mathrm{CO}_{2}\right.$ and cold) were unambiguously defined as irritating by all subjects. $^{10,11}$

\section{Stimulation of the Conjunctiva}

Basal tear secretion was not modified significantly by stimulation of the conjunctiva with air pulses of low or high flow (170 and $260 \mathrm{~mL} / \mathrm{min}$ ). Gas mixtures containing $80 \% \mathrm{CO}_{2}$ also failed to evoke an increased tear secretion (Fig. 1B). No changes in tear production were detected with cooled air pulses that reduced basal temperature at the corneal surface by $-1^{\circ} \mathrm{C}$ or $-4.5^{\circ} \mathrm{C}$, when applied at subthreshold flow rates.

Moderate or strong stimuli of all modalities applied to the conjunctiva always evoked a conscious sensation, although strong stimuli were less effective than in the cornea in producing a well-defined sensation of irritation. ${ }^{11}$

\section{Discussion}

This study analyzed the contribution of the various functional types of sensory receptor fibers that innervate the eyeball surface to increased lacrimal secretion evoked by ocular irritation and showed that the reflex augmentation of tear secretion was activated only when polymodal nociceptor fibers of the cornea were strongly stimulated. An equivalent excitation of corneal cold receptors or of polymodal nociceptors innervating the conjunctiva was ineffective in increasing tear production.

Mechanical stimulation of the cornea with the gas esthesiometer using air pulses of $170 \mathrm{~mL} / \mathrm{min}$ represents a moderate mechanical stimulation, close to threshold. Such low-intensity stimuli activate, weakly and almost exclusively, a fraction of polymodal nociceptor fibers in the cat and evoke in humans an ill-defined sensation of contact that includes a low irritation component. ${ }^{10,14}$ In contrast, mechanical stimuli of higher intensity, as those performed with air puffs of $260 \mathrm{~mL} / \mathrm{min}$, excites in cats most if not all polymodal nociceptor fibers and also the population of high-threshold mechanonociceptors. ${ }^{10}$ In humans, the same gas pulses elicited a distinct sensation of irritation. The present study demonstrates that only these high- 


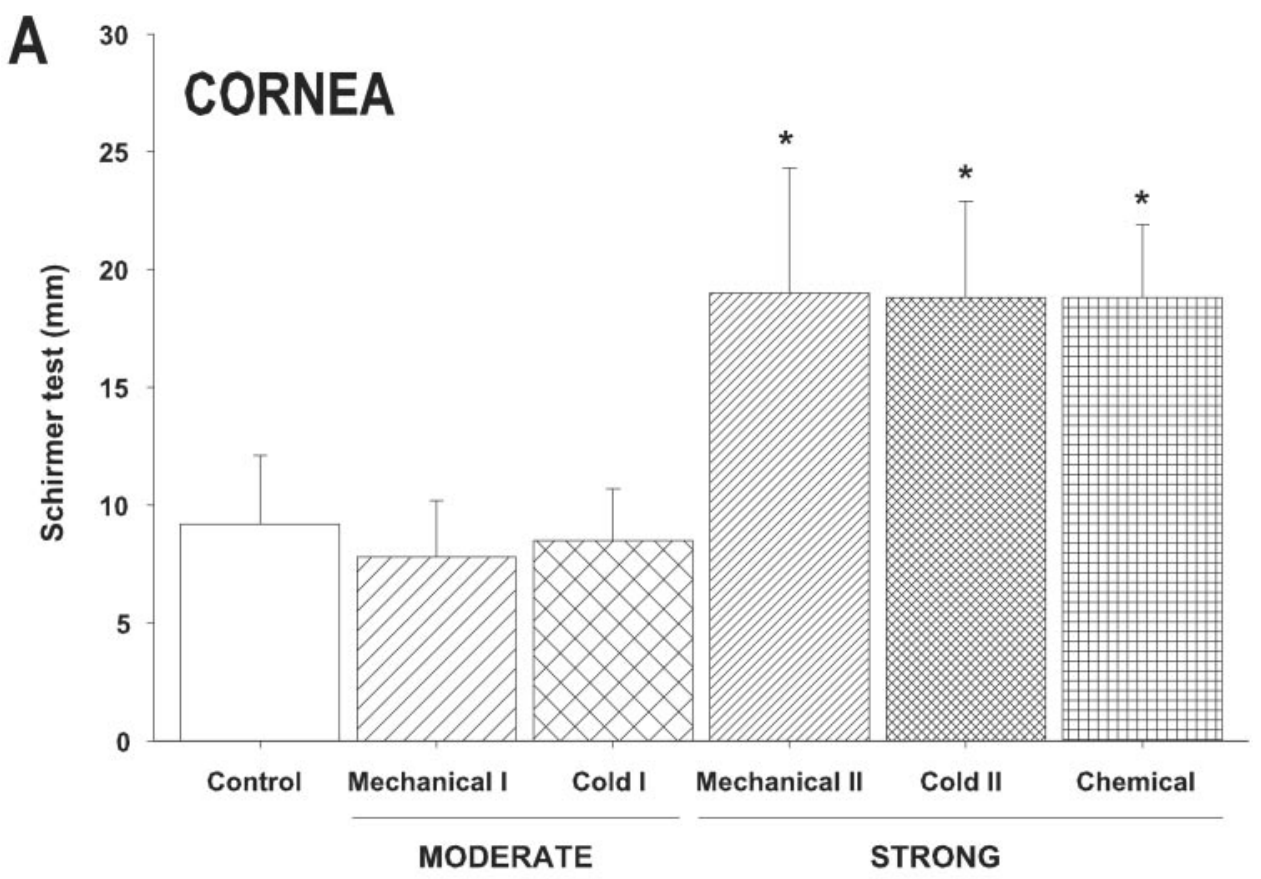

Figure 1. Tear secretion (Schirmer test) in control conditions and after moderate and strong stimulation of the center of the cornea (A) and temporal conjunctiva (B). Data from both eyes were pooled and are expressed as the mean \pm SEM in millimeters. ${ }^{*} P<0.05$, paired $t$-test.

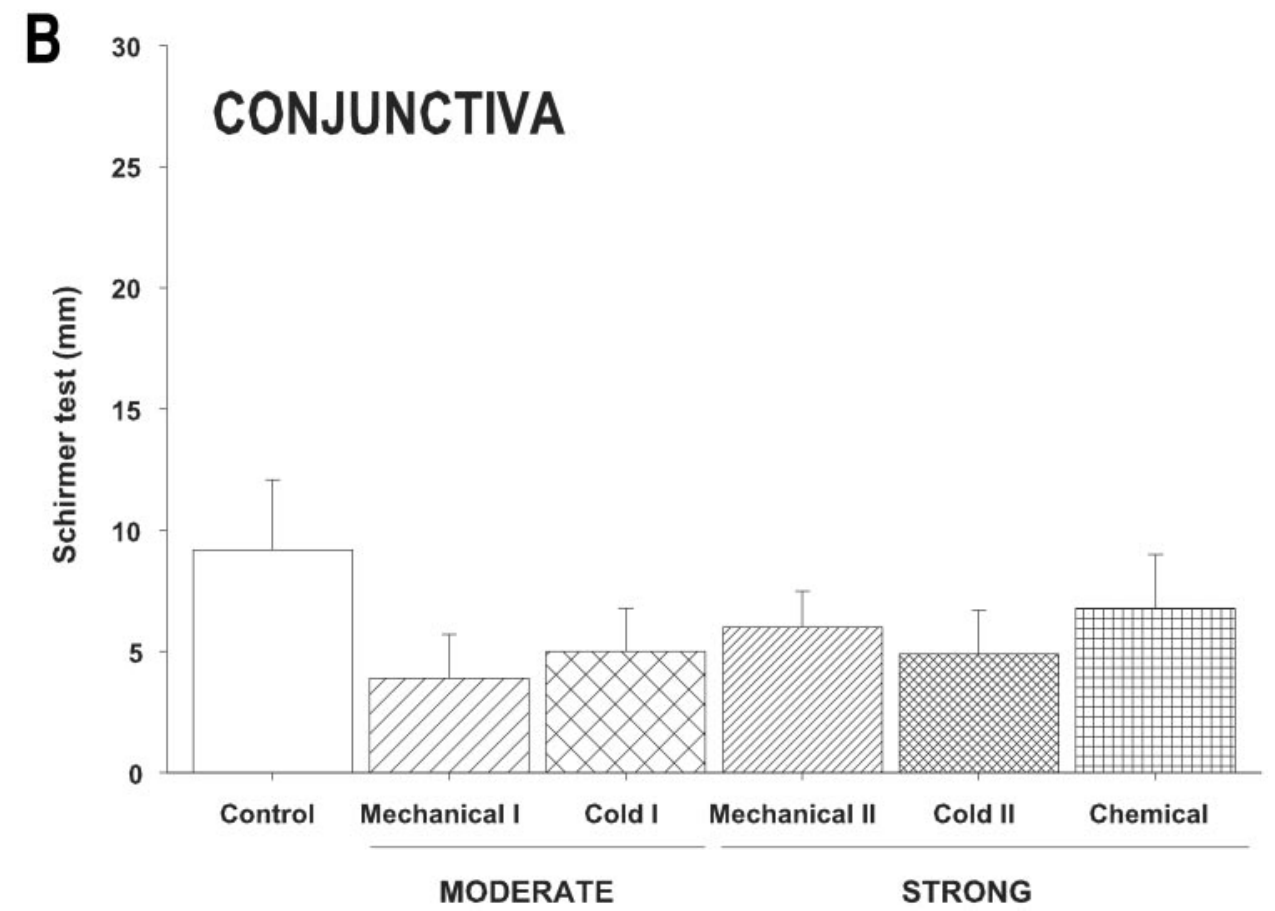

flow stimuli triggered a reflex increase in tear secretion, which suggests that recruitment of a significant part of the population of polymodal nociceptor fiber and/or of mechanonociceptor fibers is needed to trigger the reflex response leading to an increased production of tears.

Gas pulses containing a high concentration of $\mathrm{CO}_{2}(80 \%)$ form carbonic acid in the ocular surface, thus producing a local increase in proton concentration. ${ }^{6,10,14}$ This $\mathrm{pH}$ decrease acts as a chemical stimulus that activates vigorously the polymodal nociceptor fibers but not the mechanonociceptors or cold receptors. ${ }^{6,7,10,11,15} \mathrm{With} 80 \% \mathrm{CO}_{2}$ pulses, reflex tear secretion was augmented to the same levels than when a strong mechanical stimulation was applied. This observation further supports the hypothesis that stimulation of polymodal nociceptor fibers is the main mechanism for triggering the tearing reflex, whereas mechanonociceptors seem to play, at best, a secondary role in this response. This observation is not surprising, considering that pure mechanonociceptor fibers of the cornea are not abundant (approximately 30\% of the A-delta population in the feline cornea9) and give in response to a sustained stimulus, a transient discharge composed by one or few nerve impulses, in contrast with $\mathrm{A}-\delta$ and $\mathrm{C}$ polymodal nociceptors 
that fire a continuous, irregular train of nerve impulses as long as the stimulating pulse is maintained. Moreover, they represent more than $60 \%$ of the total population of corneal nerve afferents.

Stimulation of the cornea with moderate cooling (local temperature reductions of $<2^{\circ} \mathrm{C}$ ) did not increase the basal volume of tears. Small reductions of corneal temperature surface within that limit are known to activate exclusively the population of corneal cold receptor fibers and to evoke sensations of non-noxious cooling. When stronger cold is applied, a fraction of polymodal nociceptors is also recruited. ${ }^{10,16}$ Correspondingly, the sensation acquired an irritating quality ${ }^{10}$ and, as shown in this work, tear secretion was significantly increased.

In the conjunctiva, none of the stimuli that were effective in the cornea evoked an augmented tear secretion. Electrophysiological studies of the scleral innervation are still incomplete, but have evidenced the presence in this tissue of essentially the same functional types of sensory fibers that are found in the cornea, although the overall density of nerve endings in the conjunctiva appears to be comparatively lower (Aracil A, et al. IOVS 2001; 42 :ARVO Abstract 3561). ${ }^{9,17}$ Sensation thresholds for mechanical stimulation in the conjunctiva are higher than in the cornea, ${ }^{11,18,19}$ presumably due to the lower innervation density and to the fact that nerve endings innervating the conjunctival epithelium are more distant from the surface and therefore less exposed to stimuli than in the cornea. ${ }^{15}$ In addition, the rich vascularization of the conjunctiva possibly contributes to buffer thermal and $\mathrm{pH}$ effects, thereby decreasing the effectiveness of cold and $\mathrm{CO}_{2}$ stimuli in activating sensory afferents. However, strong mechanical, cold, and acidic stimuli of the conjunctiva evoked a distinct sensation of irritation in our subjects, showing that polymodal nociceptors are also excited by these stimuli. ${ }^{11}$ Thus, the differences detected in our experiments between reflex tear secretion evoked by corneal and conjunctival stimulation may be due to a reduced recruitment of polymodal nociceptor fibers in the case of the conjunctiva, below the level required to activate the reflex tearing pathway. Alternatively, afferents innervating the bulbar conjunctiva may not be connected with the central neurons of the relay stations involved in the reflex control of tear secretion and would be thus unable to modify tearing. In our experimental conditions, the relative contribution to the observed changes in lacrimal secretion, of the various tissues involved in tear formation (lacrimal glands, goblet cells, epithelia) ${ }^{20}$ was not evaluated. Thus, the degree of modification of fluid production by reflex stimulation of the autonomic fibers in each of these tissues could not be determined.

The contribution of the background impulse activity of corneal and conjunctival sensory nerve afferents to the basal lacrimal secretion, through a neural loop connected with the autonomic efferent fibers directed to the lacrimal glands is unknown. Topical anesthesia of the cornea and conjunctiva reduces basal production of tears by $25 \%$ to $40 \%,{ }^{21,22}$ thus speaking in favor of a tonic neural stimulation on the lacrimal secretion originated at the sensory receptors of the ocular surface. It is noteworthy though that only cold thermoreceptor corneal fibers discharge spontaneously at rest, whereas mechano- and polymodal nociceptors fire occasional impulses or remain silent unless noxious stimulation is applied to the cornea, thus suggesting that cold receptor fibers provide the main afferent input for the hypothetical neural component of the basal tear secretion. Nevertheless, moderate cooling of the cornea, which evokes a marked increase in the discharge of corneal cold receptor fibers ${ }^{7}$ did not induce an augmented tear secretion. It can be speculated that the fraction of the basal lacrimal secretion that depends on a neural input from cold receptor fibers is already activated at its maximum level by the ongoing activity of these fibers at rest. In contrast, reflex secretion caused by irritating stimuli may follow a separate afferent pathway, whose peripheral branch is composed chiefly of corneal polymodal nociceptor fibers.

\section{References}

1. Mutch JR. The lacrimation reflex. Br J Ophthalmol. 1944;28:317336.

2. Drummond PD. Lacrimation and cutaneous vasodilatation in the face induced by painful stimulation of the nasal ala and upper lid. J Auton Nerv Syst. 1995;51:109-116.

3. Whitwell $\mathrm{J}$. Role of the sympathetic in lacrimal secretion. $\mathrm{Br} J$ Ophthalmol. 1961;45:439-445.

4. Ding C, Walcott B, Keyser KT. Sympathetic neural control of the mouse lacrimal gland. Invest Ophthalmol Vis Sci. 2003;44:15131520.

5. Dartt DA. Control of mucin production by ocular surface epithelial cells. Exp Eye Res. 2004;78:173-185.

6. Belmonte C, Gallar J, Pozo MA, Rebollo I. Excitation by irritant chemical substances of sensory afferent units in the cat's cornea. J Physiol. 1991;437:709-725.

7. Gallar J, Pozo MA, Tuckett RP, Belmonte C. Response of sensory units with unmyelinated fibers to mechanical, thermal and chemical stimulation of the cat's cornea. J Physiol. 1993;468:609-622.

8. Belmonte C, Gallar J. Corneal nociceptors. In: Belmonte C, Cervero F, eds. Neurobiology of Nociceptors. Oxford, UK: Oxford University Press; 1996;146-183.

9. Belmonte C, Garcia-Hirschfeld J, Gallar J. Neurobiology of ocular pain. Prog Retin Eye Res. 1997;16:117-156.

10. Acosta MC, Belmonte C, Gallar J. Sensory experiences in humans and single unit activity in cats evoked by polymodal stimulation of the cornea. J Physiol. 2001;534:511-525.

11. Acosta MC, Tan EM, Belmonte C, Gallar J. Sensations evoked by selective mechanical, chemical and thermal stimulation of the conjunctiva and cornea. Invest Ophthalmol Vis Sci. 2001;42: 2063-2067.

12. Belmonte C, Acosta MC, Schmelz M, Gallar J. Measurement of corneal sensitivity to mechanical and chemical stimuli with $\mathrm{a} \mathrm{CO}_{2}$ esthesiometer. Invest Ophthalmol Vis Sci. 1999;40:513-519.

13. Schirmer O. Studien zur Physiologie and Pathologie der Träneabsonderung und Tränenabfuhr. Graefes Arch Ophthalmol. 1903;56: 197-291.

14. Chen X, Gallar J, Pozo MA, Baeza M, Belmonte C. $\mathrm{CO}_{2}$ stimulation of the cornea: a comparison between human sensation and nerve activity in polymodal nociceptive afferents of the cat. Eur J Neurosci. 1995;7:1154-1163.

15. Reeh PW, Steen KH. Tissue acidosis in nociception and pain. Prog Brain Res. 1996;133:143-151.

16. Campero M, SerraJ, Ochoa JL. C-polymodal nociceptors activated by noxious low temperature in human skin. J Physiol. 1996;497: 565-572.

17. Duke-Elder S, Wybar KC. The anatomy of the visual system. Syst Ophthalmol. 1961;2:540-558.

18. Boberg-Ans J. Experience in clinical examination of corneal sensitivity. Br J Ophthalmol. 1955;309:705-726.

19. Norn MS. Conjunctival sensitivity in normal eyes. Acta Ophthalmol. 1973;51:58-66.

20. Dartt DA. Regulation of mucin and fluid secretion by conjunctival epithelial cells. Prog Retin Eye Res. 2002;21:555-576.

21. Lamberts DW, Foster CS, Perry HD. Schirmer test after topical anesthesia and the tear meniscus height in normal eyes. Arch Ophthalmol. 1979;97:1082-1085.

22. Herreras JM, Perez S, Perez H, Calonge M, Pastor JC. Influence of topical anesthesia on test diagnostic of blepharitis-associated dry eye syndrome. Ocul Immunol Inflamm. 1997;5:33-41. 